\title{
O DESEMPENHO ACADÊMICO E AS AÇÕES AFIRMATIVAS NO ENSINO MÉDIO
}

\begin{abstract}
Alex Lara Martins ${ }^{1}$
RESUMO: O advento da Lei 12.711/2012, que trata das ações afirmativas nas Instituições Federais de Ensino, causou certa polêmica sobre a sua eficácia e o senso de igualdade. O objetivo do artigo é promover um estudo de caso sobre a gestão das cotas em uma instituição de nível médio, por meio da análise descritiva e quantitativa do desempenho acadêmico dos estudantes. Serão utilizadas técnicas de coleta e análise de dados a partir do Coeficiente Trimestral de Rendimento e da Média Final de cada aluno por ano do curso, de modo a comparar o rendimento dos cotistas e não cotistas ao longo dos três anos do curso. Para inferir a diferença de rendimento, essa pesquisa utilizará o ANOVA, método estatístico que estima a variância entre grupos.
\end{abstract}

PALAVRAS-CHAVE: Cotas. Políticas Afirmativas. Ensino Médio.

\section{ACADEMIC PERFORMANCE AND AFFIRMATIVE ACTIONS IN HIGH SCHOOL}

\begin{abstract}
The Brazilian Law 12,711/2012 that regulates affirmative action in the Federal Institutions of Education caused some controversies about its effectiveness and the sense of equality. The aim of the paper is to promote a case study on this public policy in the Federal Institute of the North of Minas Gerais - Campus Almenara, through a descriptive analysis of the high school students' academic performance. The nature of the research is quantitative, since data collection and analysis techniques will be used from the Quarterly Student Achievement Coefficient and the Average Annual Score, in order to compare the income of the quota and non-quota students. This research will use the ANOVA, a statistical model for estimates the variance among and between groups.
\end{abstract}

KEYWORDS: Quotas. Affirmative Policies. High School.

\section{EL DESEMPEÑO ACADÉMICO Y LAS ACCIONES AFIRMATIVAS EN LA EDUCACIÓN SECUNDARIA}

RESUMEN: La sancion de la Ley 12.711/2012, que trata de las acciones afirmativas en las Instituciones Federales de Educación, causó cierta polémica sobre su eficacia y el sentido de equidad. El objetivo de este articulo es promover un estudio de caso sobre la gestión de las cuotas escolares en una institución de grado medio, a través del análisis

\footnotetext{
${ }^{1}$ Professor do Instituto Federal de Educação, Ciência e Tecnologia do Norte de Minas Gerais, Campus Pirapora. Docente do Programa de Pós-Graduação em Educação Profissional e Tecnológica (ProfEPT), Campus Montes Claros.
} 
descriptivo y cuantitativo del desempeño académico de los estudiantes. Se utilizarán técnicas de recolección y análisis de datos recogidos a partir del Coeficiente Trimestral de Rendimiento y de la Media Final de cada alumno por año del curso, para comparar el rendimiento de los cuotistas y no cuotistas a lo largo de los tres años del curso. Para inferir la diferencia de rendimiento, esta investigación utilizará el ANOVA, método estadístico de análisis de varianza.

PALABRAS CLAVE: Cotas. Políticas Afirmativas. Enseñanza Media.

\section{INTRODUÇÃO}

A Lei ordinária $n^{\circ}$ 12.711/2012, também conhecida como "lei de cotas", modificou o modo de ingresso nas Universidades Públicas e nas Instituições Federais de Ensino Técnico de Nível Médio. Essa norma trouxe para a ordem do dia o debate sobre a função do Estado no que diz respeito à promoção de políticas públicas no âmbito da educação. As políticas públicas resultam dos conflitos de interesse de diversos atores sociais, cujas negociações visam à formulação de propostas e tomadas de decisão a serem implementadas pelas organizações de estado. No caso em questão, existe um conflito entre os interesses individuais, vinculados aos princípios de isonomia e de igualdade de tratamento, e os deveres públicos, direcionados a sanar as desigualdades sociais existentes. As ações afirmativas são planejadas e instituídas até que se ajuste a diferença de oportunidades para os diferentes estratos sociais. Acreditamos que antes e depois da tomada de decisão, o agente público deve proceder à formação de agenda e de alternativas para resolução do problema, de maneira que a implementação e a execução das decisões sejam acompanhadas de um monitoramento exaustivo. No caso das cotas para ingresso em instituições públicas de ensino, há estudos que realizam o monitoramento do desde o ingresso na instituição, com abordagem quantitativa relacionada ao ingresso de cotistas (ADAMS, 2019), ao desempenho acadêmico (ARAÚJO, 2019; CHAVES et al., 2020) e com abordagem qualitativa relacionada à percepção acadêmica e institucional sobre os efeitos da Lei de Cotas (MIRANDA, 2017). Há ainda pesquisas que avaliam impacto social dos beneficiários dos programas pela continuidade de estudos dos egressos e a sua inserção no mercado de trabalho (PINHEIRO, 2020). Seja como for, a maior parte dos estudos sobre desempenho acadêmico de cotistas aplicam-se ao ensino superior (VELLOSO, 2009; QUEIROZ; SANTOS, 2006; PINHEIRO, 2014; GUERRINI et al., 2018; CASTRO et al., 2017; KARRUZ, 2018). 
A Lei 12.711 estabelece o prazo de 10 anos para a reavaliação desta política pública. De acordo com Piovesan (2005, p. 50), “ações afirmativas são medidas especiais e temporárias que buscam remediar um passado discriminatório, objetivam acelerar o processo com o alcance da igualdade substantiva por parte dos grupos socialmente vulneráveis". De acordo com Mészáros (2014), igualdade substantiva é a capacidade de os indivíduos produzirem e reorientarem suas vidas de modo associativo, horizontalmente, contrapondo-se à igualdade formal da lei, que acaba hierarquizando as pessoas conforme o seu capital econômico.

Em relação à educação brasileira, as discussões entre os diversos atores do governo e da sociedade civil deram origem à Constituição de 1988, que reconheceu como foco de reparação e justiça social as desigualdades econômicas, raciais e geográficas historicamente consolidadas no país. Antes da redemocratização, diversas entidades e movimentos negros surgiram, em escala nacional, com objetivos comuns a outros grupos historicamente oprimidos (DOMINGUES, 2007, p. 115-116).

O Governo Federal ampliou, entre 2012 e 2016, o grupo de beneficiários pela lei das cotas, após longo debate e diversas tentativas de formular políticas públicas educacionais que fizessem frente a essas desigualdades, incluindo experiências bemsucedidas em que não houve discrepância de desempenho entre cotistas e não cotistas. Mais recentemente, a Portaria Normativa 13/2016, do Ministério da Educação, propôs a indução de ações afirmativas nos cursos de pós-graduação da rede federal de ensino. No caso do Ensino Médio, a lei das cotas estabeleceu que as instituições federais devem reservar metade das suas vagas para estudantes que cursaram integralmente o ensino fundamental em escolas públicas, e destas, metade deve ser reservada para estudantes oriundos de famílias com renda per capita igual ou inferior a 1,5 salário mínimo. Em todo caso, essas vagas serão preenchidas por autodeclarados pardos, pretos e indígenas, de acordo com a proporção verificada no censo do Instituto Brasileiro de Geografia e Estatística (IBGE).

Desde 2011, o Instituto Federal do Norte de Minas Gerais - Campus Almenara (IFNMG-Almenara) oferece vagas para os cursos técnicos de Agropecuária e Informática integrados ao Ensino Médio. No ano seguinte, a instituição passou a oferecer o curso 
técnico em Zootecnia. Em cumprimento à Lei 12.711/2012 e à Portaria Normativa 18, de 11 de outubro de 2012, expedida pelo Ministério da Educação, os editais de processos seletivos desta instituição aderiram ao sistema de reserva de vagas, que se subdivide em quatro casos de estudantes oriundos de escolas pública: VRRI - Vagas reservadas para estudante com renda familiar bruta igual ou inferior a 1,5 salário-mínimo per capita; VRRS - Vagas reservadas para estudante com renda familiar bruta superior a 1,5 saláriomínimo per capita; VRRI-PPI - Vagas reservadas para estudantes com renda familiar bruta igual ou inferior a 1,5 salário-mínimo per capita que se autodeclararem pretos, pardos e indígenas; e VRRS-PPI - Vagas reservadas para estudantes com renda familiar bruta superior a 1,5 salário-mínimo per capita que se autodeclarem pretos, pardos e indígenas. $\mathrm{O}$ artigo que tratava dos beneficiários da reserva de vagas teve a sua redação alterada pela Lei n 13.409, de 2016, que incluiu a proporção de pessoas com deficiência na população da unidade Federativa onde a instituição de ensino está instalada.

Existe uma relação de impacto positivo da expansão dos Institutos Federais, no curto prazo e em cidades de até 50 mil habitantes, nos índices de PIB per capita, salário e escolaridade médios, taxa de emprego de nível superior, Coeficiente de Gini e Índice de Desenvolvimento Humano (FAVERI et al., 2018, p. 139). Um número relevante de estudos tem analisado comparativamente o desempenho de alunos cotistas que ingressam nas Universidades, alguns dos quais destacaremos abaixo. O estudo em tela consiste em realizar um estudo de caso comparativo entre o desempenho acadêmico dos cotistas e dos não cotistas dos Cursos Técnicos Integrados ao Ensino Médio de uma instituição de ensino. Será necessário explorar os argumentos a favor e contrários às políticas de ações afirmativas, bem como identificar os fatores e as variáveis que promovem a desigualdade de desempenho entre os alunos cotistas e não cotistas. Como consequência de um raciocínio indutivo sobre os resultados obtidos em pesquisas que incidiram sobre o desempenho acadêmico dos alunos cotistas de cursos de nível superior, desenvolveu-se neste trabalho a hipótese de que as desigualdades de desempenho também tendem a ser dirimidas ao longo da vida acadêmica dos alunos do Ensino Médio.

Essa pesquisa pode contribuir tanto para a melhoria dos processos de entrada, permanência e saída dos alunos, quanto para as tomadas de decisão da gestão dos Institutos Federais, em seus diversos programas de assistência e apoio aos alunos em 
situação de vulnerabilidade socioeconômica, tais como o Núcleo de Atendimento às Pessoas com Necessidades Específicas (NAPNE), o Núcleo de Estudos Afro-brasileiros e Indígenas (NEABI) e o Núcleo de Apoio ao Estudante (NAE).

\section{REVISÃO DE LITERATURA}

Nesta seção, o escopo do fenômeno pesquisado será delimitado conceitualmente. Para realizar a revisão de literatura, seguiu-se a metodologia de natureza exploratória, que busca descobrir ideias e crenças, com a finalidade de fornecer um "esquema geral" do debate sobre as cotas, de modo a identificarmos as questões relevantes a serem respondidas e as diferentes posições sobre o tema (BIROCHI, 2015, p. 49). A análise bibliométrica, isto é, o estudo sistemático de fontes bibliográficas e técnicas de pesquisa utilizados para compreender este fenômeno, permitiu demarcar o problema e elaborar os objetivos da pesquisa, quais sejam, comparar o desempenho acadêmico dos cotistas e dos não cotistas de três cursos técnicos integrados, identificar os fatores e as variáveis correlacionadas à desigualdade de desempenho de alunos cotistas frente aos demais, e subsidiar as ações dos programas de assistência aos alunos em situação de vulnerabilidade social. Essa análise leva em conta as fontes documentais e os estudos já realizados sobre o desempenho de estudantes cotistas em algumas instituições brasileiras de nível médio e superior.

Quando falamos em políticas públicas devemos compreendê-las dentro de contextos maiores, sejam eles nacionais ou internacionais, uma vez que elas estão submetidas e, algumas vezes até contrapostas, a relações de poder que se perpetuam ao longo da história, com implicações variadas. Essas políticas se justificam em diversos campos de debate, com audiências igualmente diversas (RUA, 2014, p. 17). Além de permitir o acesso às instituições públicas de ensino, o mecanismo das cotas consolida-se em outros setores da sociedade brasileira, como as ações afirmativas para ingresso no funcionalismo público e a reserva de vagas para mulheres nas casas Legislativas.

De acordo com Feres Júnior (2006), os argumentos que justificam as ações afirmativas podem ser agrupados em três classes: reparação, justiça distributiva e diversidade. Além do Brasil, países como Austrália, África do Sul, Canadá, Colômbia, Estados Unidos, Índia, Irlanda do Norte, Líbano, Malásia e Noruega mantém sistemas de 
cotas, de bônus, financiamento e metas de inclusão para grupos raciais, étnicos, religiosos ou castas. De maneira geral, trata-se de uma política de Estado que não está imune, porém, às mudanças ideológicas de governo.

Nos Estados Unidos, o relatório Igualdade de Oportunidades Educacionais foi o propulsor das políticas de redução de desigualdades educacionais, ao revelar a discrepância nos níveis de desempenho educacional de grupos étnicos/raciais, com benefício, em todos os casos, para os brancos (MONSTELLER; MOYNIHAN, 2008, p. 37-38). As ações afirmativas, nos Estados Unidos, são realizadas, desde a década de 1960, pelo setor público, por entidades sem fins lucrativos e pela iniciativa privada, em geral concedendo uma "vantagem adicional" (boost) ao candidato pertencente ao grupo cotista (WEISSKOPF, 2008, p. 37). No Brasil, a discussão sobre ações afirmativas no âmbito educacional ganhou força na primeira década deste século, após a adoção da Resolução aprovada na Conferência de Duban (2001) e o compromisso do país em relação à aplicação de ações para combate ao racismo (ALVES, 2002).

O sistema de reserva de vagas está vinculado a uma razão histórica de redução das oportunidades de um grupo social na formação escolar e em sua participação em nichos do mercado de trabalho. Assim, a ideia de reparação tem como premissa a instituição ou a restauração de igualdades relacionadas a direitos civis, sociais e políticos. É claro que a reparação contra a discriminação ocorrida outrora devido à raça e ao credo ocorre em detrimento dos talentos e habilidades naturais dos indivíduos no presente, que podem alegar nunca terem sido parte de atos discriminatórios, não podendo ser responsabilizados por crimes do passado - ou de seus antepassados. Ao contrário, o fato de estarem sendo preteridos em concurso objetivo pode ser entendido como um ato discriminatório ou um ato que não observa o princípio da isonomia. Levando às últimas consequências, a diversidade cultural diminui a importância do argumento da reparação histórica, pois os indivíduos podem sempre se incluir em uma das minorias a serem protegidas (FERES JUNIOR, 2006, p. 9-10), ainda mais em um país que apresenta alto grau de miscigenação, como o Brasil.

Apesar disso, pode-se recuperar a força do argumento reparativo recorrendo-se à noção de justiça social/distributiva, ou seja, a concepção de que as políticas públicas 
devem visar ao benefício e ao interesse social, em detrimento dos interesses privados individuais. De acordo com o filósofo John Rawls, a justiça como equidade deve se basear em dois princípios, quais sejam:

(a) cada pessoa tem o mesmo direito irrevogável a um esquema plenamente adequado de direitos e de liberdades básicas iguais, que seja compatível com o mesmo esquema de liberdades para todos; e (b) as desigualdades sociais e econômicas devem satisfazer duas condições: primeiro, devem estar vinculadas a cargos e a posições acessíveis a todos, em condições de igualdade equitativa de oportunidades, e, segundo, têm de beneficiar ao máximo os membros menos favorecidos da sociedade (RAWLS, 2003, p. 60).

O princípio do mérito, entendido na comparação de resultados individuais em um concurso, é substituído pelo princípio de nivelamento, em que indivíduos em condições desiguais são tratados de maneira desigual, até que se promova o nivelamento inicial da competição, satisfazendo os dois princípios elencados por Rawls. Após o nivelamento, o princípio do mérito se torna compatível com o princípio da isonomia. Em julgamento sobre a constitucionalidade das ações afirmativas, especificamente sobre a reserva de vagas para negros na Universidade de Brasília, o Supremo Tribunal Federal indeferiu o pedido de medida cautelar em Arguição de Descumprimento de Preceito Fundamental (ADPF 186-2) contra o sistema de cotas, recorrendo ao espírito constitucional de reparação e justiça social (STF, 2009), seguindo-se do voto do relator do processo afirmando que as políticas de ações afirmativas:

(i) têm como objetivo estabelecer um ambiente acadêmico plural e diversificado, superando distorções sociais historicamente consolidadas, (ii) revelam proporcionalidade e a razoabilidade no concernente aos meios empregados e aos fins perseguidos, (iii) são transitórias e preveem a revisão periódica de seus resultados, e (iv) empregam métodos seletivos eficazes e compatíveis com o princípio da dignidade humana (LEWANDOWSKI, 2012, p. 47).

Com argumentação semelhante, este plenário jurisdicional, por meio da Ação Declaratória de Constitucionalidade 41, declarou a constitucionalidade da Lei 12.990/2014 que estabeleceu cotas étnico-raciais nos concursos públicos federais. O relator Ministro Roberto Barroso anotou que

a adoção pelo Estado de medidas concretas direcionadas a assegurar o desenvolvimento humano de minorias historicamente discriminadas conforma-se aos princípios postos na Constituição da República (BARROSO, 2017, p. 13). 
O que se visou em ambos julgamentos, em termos de custo-benefício, não foi apenas a distribuição de rendas, mas a distribuição de cidadania equitativa e cooperação social assegurados pelo Estado. Neste caso, a democracia é uma construção coletiva de atores provisoriamente em conflito, mas que são induzidos a cooperar. Desse modo, a agenda, a análise do problema, a tomada de decisão e os ajustes podem sofrer alterações dependendo da configuração da arena política e dos interesses de um ou mais atores dentro do grupo de poder, mesmo que o objetivo da política pública beneficie um dos grupos em conflito, neste caso, os "membros menos favorecidos da sociedade" ou as "minorias historicamente discriminadas".

Uma das demandas recorrentes do debate político é a visibilidade e conhecimento das culturas de matriz africana. Essa demanda se justifica historicamente, pois é parte de nossa própria identidade, que teimamos em renegar e relegar a segundo plano. Dados do IPEA revelaram que mais da metade dos brasileiros autodeclararam ascendência afro-brasileira, e a Pesquisa Nacional por Amostra de Domicílios Contínua (2018) indica a tendência de crescimento da população autodeclarada preta e diminuição da autodeclarada branca em proporção de 30\% no decênio de 2010-2020, muito embora exista uma ideologia de branqueamento, que torna equívoca a autovisão individual (FERES JÚNIOR, 2006, p 12). Este equívoco se revela na PNAD Contínua, realizada pelo IBGE, segundo a qual, em 2018, os brancos correspondem a 43,1\%, os pardos a $46,5 \%$ e os pretos a apenas 9,3\% das autodeclarações (IBGE, 2019). Além disso, é mais ou menos consensual que a desigualdade e o preconceito racial ainda se perpetuam, por exemplo, nos índices de analfabetismo, média salarial, cargos de chefia (IPEA, 2009; IBGE, 2018), escolaridade e inserção no mercado de trabalho (GUIMARÃES et al., 2019), daí a necessidade, explícita na Constituição, de proteger os grupos de matrizes africanas e indígenas.

A Lei $\mathrm{n}^{\mathrm{o}} 10.639$, de 9 de janeiro de 2003, modificada pela Lei $\mathrm{N}^{\mathrm{o}} 11.645$, de 10 março de 2008, estabeleceu as diretrizes para o ensino de temáticas da história e das culturas afro-brasileiras (e indígenas) nos ensinos fundamental e médio, dando ao artigo 26-A da LDB a seguinte redação: 
Nos estabelecimentos de ensino fundamental e de ensino médio, públicos e privados, torna-se obrigatório o estudo da história e cultura afro-brasileira e indígena.

§ 1o O conteúdo programático a que se refere este artigo incluirá diversos aspectos da história e da cultura que caracterizam a formação da população brasileira, a partir desses dois grupos étnicos, tais como o estudo da história da África e dos africanos, a luta dos negros e dos povos indígenas no Brasil, a cultura negra e indígena brasileira e o negro e o índio na formação da sociedade nacional, resgatando as suas contribuições nas áreas social, econômica e política, pertinentes à história do Brasil.

§ 20 Os conteúdos referentes à história e cultura afro-brasileira e dos povos indígenas brasileiros serão ministrados no âmbito de todo o currículo escolar, em especial nas áreas de educação artística e de literatura e história brasileiras.

De lá para cá, as instituições de ensino vêm se esforçando para garantir o cumprimento da lei, implementando a agenda maior que diz respeito à política de ações afirmativas. De acordo com Campos (2013, p. 66), os principais argumentos contrários às políticas de ações afirmativas, disseminados pela imprensa, são o acirramento dos conflitos social e racial, determinando uma discriminação às avessas, e que pode até estigmatizar os beneficiários; a ineficiência no combate à desigualdade, pois, além de medida eleitoreira, é uma solução paliativa de intervenção estatal nas relações sociais; diminuição da qualidade do ensino e produz profissionais despreparados; e desrespeito ao princípio jurídico e moral da igualdade, deixando de lado o mérito pessoal do grupo que teria melhor desempenho no processo avaliativo. Ainda de acordo com Campos (2013), os principais argumentos a favor das políticas de ações afirmativas, disseminados pela imprensa, são a diminuição dos conflitos social e racial, produzindo o combate à discriminação e ao racismo, que pode até emancipar os beneficiários, que passam a competir em igualdade de condições; a promoção da boa política republicana de inserção social, produz a diversidade no processo de ensino-aprendizagem, dissociando a cor da ideia de pobreza, respeita ao princípio constitucional e ético da igualdade formal de condições; além de ser uma medida emergencial que pretende dirimir os efeitos da escravidão e outros processos históricos de exclusão social.

Apesar de os argumentos se contraporem, estudos recentes trazem evidências de que, pelo menos nas Universidades Públicas situadas em centros urbanos, as políticas de ações afirmativas são bem-sucedidas quanto ao desempenho escolar, no âmbito do 
Distrito Federal (VELLOSO, 2009) e dos Estados da Bahia (QUEIROZ; SANTOS, 2006), do Espírito Santo (PINHEIRO, 2014), do Paraná (GUERRINI et al., 2018) e de Minas Gerais (CASTRO et al., 2017; KARRUZ, 2018). Em todos estes casos, as notas de cotistas e não cotistas tendem a se igualar no médio prazo. Nesse sentido, a hipótese deste trabalho é que essa tendência se manterá entre os ingressantes cotistas e não cotistas de cursos de Ensino Médio, ainda que, considerando separadamente algum subgrupo cotista, a diferença de desempenho possa ser significativa.

Ao discutir os conceitos e os argumentos sobre as políticas de ações afirmativas, especificamente a política de cotas implementada pela lei $\mathrm{n}^{\circ} 12.711 / 2012$, pode-se considerar, com base em experiências prévias, os benefícios da sua implementação no curto e no médio prazos, como forma de redução das desigualdades sociais, dirimindo a base formativa precária do Ensino Fundamental e oportunizando o acesso a um curso qualquer em nível superior. Esta revisão de literatura forneceu os subsídios contextuais para a análise quantitativa do desempenho dos alunos de ensino médio cotistas e não cotistas no âmbito do IFNMG-Almenara.

\section{PERCURSO METODOLÓGICO}

A natureza desta pesquisa é descritiva, cuja finalidade consiste em delinear certa população ou fenômeno a partir do estabelecimento de variáveis e da relação que elas travam entre si. Este tipo de pesquisa requer a adoção de um paradigma ou a utilização de técnicas de coleta de dados, que permitem descrever o fenômeno, uma situação ou as características de um indivíduo e uma população com maior exatidão, além de desvelar a relação, causal ou correlacional, entre os eventos conforme as variáveis relacionadas ao desempenho escolar. Essa pesquisa fundamentou-se em Triola (2015) em relação aos procedimentos estatísticos. O estudo metodológico está dividido em três seções, em que são apresentados a metodologia utilizada para coleta, análise de dados e a manipulação estatística, os resultados obtidos e a interpretação analítica dos resultados. 
ISSN: 2594-4827

\section{Distribuição amostral}

Os fenômenos estudados foram descritos a partir de um estudo retrospectivo, cujos dados foram coletados sobre o período de 2013 a 2017. A fonte de dados da Secretaria Escolar está armazenada no banco do Sistema Acadêmico de Gestão Unificada do Instituto Federal do Norte de Minas Gerais (SAGU). Considerou-se como população o conjunto de todos os 503 alunos matriculados nos cursos técnicos integrados ao Ensino Médio entre 2013 e 2017. A amostragem por quotas foi estabelecida para o conjunto de alunos matriculados em 2014 no $1^{\circ}$ ano dos cursos técnicos integrados ao Ensino Médio do IFNMG-Almenara, nas áreas de Agropecuária, Informática e Zootecnia, totalizando 73 estudantes.

Monitorou-se o desempenho acadêmico da amostra dos estudantes das turmas ingressantes em 2014 até a sua formatura em 2016, comparando o desempenho dessa turma com a média das notas da população. Os subconjuntos dessa amostra se dividiram em cotistas e não cotistas e, entre aqueles, em cotistas cujos rótulos seguem os parâmetros genéricos de proveniência escolar; cotistas por parâmetros de renda e proveniência escolar; e cotistas por parâmetros de raça/etnia, renda e proveniência escolar.

Esses parâmetros foram tratados de maneira quantitativa e discreta, isto é, observando-se a medida do rendimento escolar apresentado em boletim em escala de 0 a 100 para cada disciplina cursada. Utilizou-se, também, um parâmetro inicial relativo à classificação no processo seletivo para ingresso no curso, que variou em escala de 0 a 30 . Considerando a população total de alunos atuais e dos egressos de cursos integrados do IFNMG, pode-se dizer que a pesquisa lidou com a amostragem estratificada de grupos (coortes) com características iguais. Nesse caso, beneficiou-se do planejamento de dados emparelhados, pois os grupos de tratamento possuem características similares e exclusivas (cotistas ou não cotistas, renda acima ou abaixo de 1 salário-mínimo e meio etc.), tal como se pode ver na Tabela 1.

Essa contagem desconsiderou 7 registros sem informação de modalidade e 3 registros de reserva de vagas para pessoas com deficiência. Para manter o emparelhamento de notas dos alunos com entrada em 2014, considerou-se no cômputo aqueles que tiveram êxito em completar, pelo menos, os dois primeiros anos do curso e 
que tiveram notas até o terceiro trimestre do último ano. Os alunos evadidos e retidos até o final do segundo ano foram registrados e tabulados separadamente, gerando resultados que podem servir a programas institucionais de êxito e permanência.

Tabela 1 - Amostra estratificada de alunos do IFNMG-Almenara a partir da Lei $12.711 / 2012$.

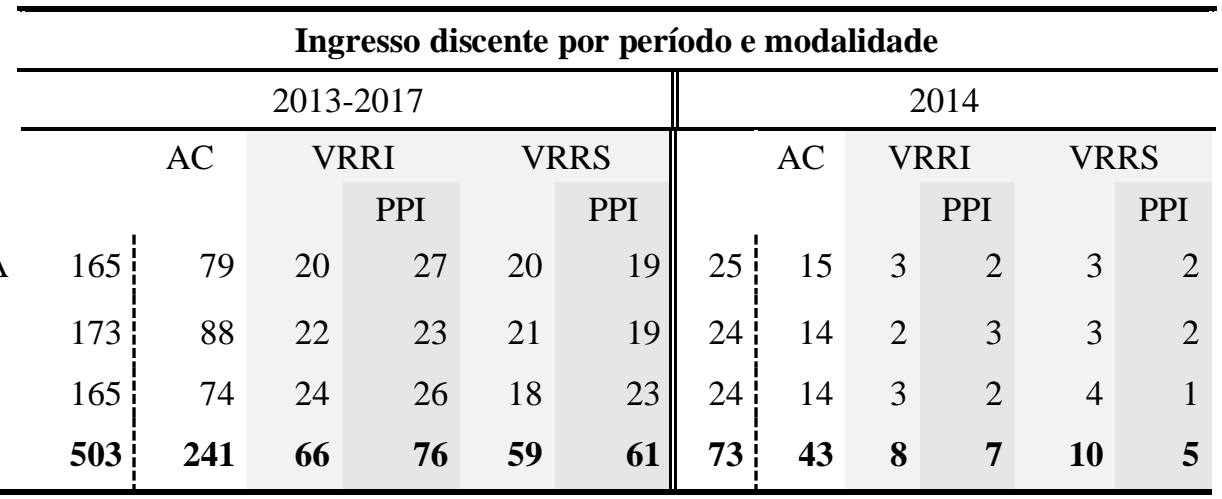

Fonte: Secretaria Escolar do IFNMG-Almenara (2018)

Siglas: AC: Ampla Concorrência; VRRI: Vagas reservadas para estudante com renda familiar bruta igual ou inferior a 1,5 salário-mínimo per capita; VRRS: Vagas reservadas para estudante com renda familiar bruta superior a 1,5 salário-mínimo per capita; PPI: Estudantes que se autodeclararam pretos, pardos ou indígenas.

\section{Coeficiente de Rendimento Acadêmico (CRA)}

Além do desempenho escolar durante o Ensino Médio, avaliaram-se dados relativos ao desempenho no processo seletivo de ingresso na instituição, com pontuações nas áreas de Ciências da Natureza e Exatas (máximo de 16 pontos) e Ciências Humanas e Linguagens (máximo de 14 pontos). Durante o Ensino Médio, a quantidade de disciplinas analisadas por curso e por ano estão discriminadas na Tabela 2:

Tabela 2 - Resultados de notas / disciplinas por curso e período das turmas com ingresso em 2014.

\begin{tabular}{c|cccc}
\hline TURMA & $\mathbf{1}^{\mathbf{0}}$ ano & $\mathbf{2}^{\mathbf{o}}$ ano & $\mathbf{3}^{\mathbf{o}}$ ano & Total \\
\hline AGROPECUÁRIA & $390 / 17$ & $432 / 18$ & $432 / 18$ & $1254 / 53$ \\
\hline INFORMÁTICA & $425 / 17$ & $425 / 17$ & $400 / 16$ & $1250 / 50$ \\
\hline ZOOTECNIA & $414 / 18$ & $413 / 18$ & $391 / 17$ & $1218 / 53$ \\
\hline
\end{tabular}

Fonte: Secretaria Escolar do IFNMG-Almenara (2018). 
O conjunto de dados considerado para a comparação entre os grupos foi o Coeficiente de Rendimento Acadêmico (CRA), isto é, a média aritmética da pontuação obtida em todas as disciplinas cursadas. A fórmula utilizada para se encontrar a média foi $\bar{x}=\frac{\sum x}{n}$, tal que para cada aluno ou grupo de alunos $(x)$, a média $(\bar{x})$ é a soma de todas as notas $\left(\sum x\right)$ dividido pelo número de disciplinas cursadas no período $(n)$. Para se calcular o desvio-padrão amostral (s), utilizou-se a seguinte fórmula: $s=\sqrt{\frac{\sum(x-\bar{x})^{2}}{n-1}}$. O desvio-padrão do CRA indicará, no Gráfico 2, a variabilidade de notas médias entre os grupos. Quanto menor o desvio-padrão, mais homogêneas são as notas individuais.

\section{Hipóteses}

Por conseguinte, os coeficientes de variação da amostra (alunos com entrada em 2014) e da população (matriculados entre 2013 e 2017) foram obtidos dividindo-se o desvio-padrão (respectivamente, $s$ ou $\sigma$ ) pela média $(\bar{x}$ ou $\mu$ ), multiplicando-se, em seguida, o resultado por $100 \%$. O mesmo resultado pode ser alcançado tomando-se a variação dentro dos subgrupos (cotistas), e comparando-a, em seguida, com a quota amostral (cotistas e não cotistas). A amostragem por quotas pré-estabelecidas em número relativamente acanhado não permite calcular de maneira precisa a margem de erro e o intervalo de confiança. Para testar as hipóteses, utilizaremos o nível de confiança comum como $\alpha=0,05$ ( $\mathrm{p}$-valor). A hipótese principal de pesquisa é que não se pode afirmar que a diferença do Coeficiente de Rendimento Acadêmico (CRA) dos alunos cotistas e nãocotistas, ao final dos três anos de Ensino Médio, tenha relevância estatística. A hipótese secundária é de que o CRA de ao menos um grupo de cotistas, ao final dos três anos, possui relevância estatística quando comparado ao grupo de não-cotistas.

\section{Análise de variância}

As variáveis foram compiladas conforme os diversos tipos de tratamento, isto é, variáveis independentes tais como o tipo de cota, o curso técnico e o desempenho por disciplina. Os valores de dados estão expressos em até uma casa decimal, exceto para o p-valor, que deve ser aferido com precisão de três casas decimais. Essa distribuição permite a compreensão e a interpretação do desvio-padrão, da variância e das tendências lineares dos grupos de alunos. Para organização e descrição estatística dos dados, utilizou- 
se a técnica de análise de variância de um fator, também conhecida como ANOVA. Essa técnica permitiu avaliar a existência de diferenças significativas entre as médias de dois ou mais grupos conforme a influência de uma ou mais variáveis. Assim, podemos testar as hipóteses de pesquisa utilizando-se a seguinte fórmula (teste F):

$$
\mathrm{F}=\frac{\text { Variância entre amostras (médias) }}{\text { Variância dentro das amostras (médias) }}
$$

A variância entre as amostras é calculada em $n$ vezes a variância das médias amostrais, tal que $n$ é o tamanho de cada uma das amostras (cotistas e não-cotistas por curso). A variância dentro das amostras é estimada calculando-se a variância combinada. O teste consiste em dividir a variação entre as médias amostrais pela variação entre os indivíduos de uma mesma amostra. A análise de variância de um fator é um método que serve para testar a igualdade de médias populacionais a partir de dados categorizados por um tratamento. Grandes valores de $F$ sugerem diferenças significativas entre médias. Por isso, a margem de significância estatística dos resultados, estabelecida em 0,05 (valor-p), será decidida quando as unidades do experimento forem homogêneas, isto é, quando pudermos realizar o delineamento experimental com a mesma chance para todos os tratamentos disponíveis. No caso dessa pesquisa, a significância estatística entre o desempenho de cotistas e não cotistas é revelada na Tabela 4.

Os resultados desta pesquisa quantitativa podem ser resumidos em tabelas e gráficos. Para as apresentações de dados, definições e fórmulas estatísticas, consultou-se Triola (2015, p. 506-510). Os gráficos e as tabelas foram elaborados com base nas informações disponibilizadas pela Secretaria Escolar do Campus Almenara, pelo SAGU e pelo resultado do processo seletivo para ingresso nos cursos técnicos, disponível no site da instituição de ensino.

\section{ANÁLISE E DISCUSSÃO DOS RESULTADOS}

A Portaria Normativa 18, de 11 de outubro de 2012 (MEC), estabeleceu o mínimo de reserva de vagas nos vestibulares da rede federal de ensino para os estudantes egressos de escola pública. No caso do IFNMG-Almenara, entre 2013 e 2017, 262 alunos ingressaram pelo sistema de cotas, ao passo que 241 ingressaram por ampla concorrência 
(Tab. 1). Essa diferença ocorre porque quando for o caso de o candidato cotista conseguir pontuação suficiente para ser classificado no sistema de ampla concorrência, ele preencherá uma das vagas deste sistema. Daí a possibilidade de o número total de cotistas ser maior do que o de não cotistas.

O Gráfico 1 revela a diferença da distribuição de notas do processo seletivo no IFNMG para as turmas ingressantes em 2014. Pode-se toma-la como um marcador para a diferença inicial de desempenho entre cotistas e não cotistas, de modo a possibilitar uma avaliação da eficácia escolar, seja quanto ao suporte das políticas de assistência estudantil, seja quanto às variáveis pedagógicas e a estimação do efeito da escola, caso se queira compará-la a outras instituições da microrregião. O eixo horizontal exibe a escala de pontuação de 0 a 16 referente aos conteúdos de Ciências da Natureza e Ciências Exatas. O eixo vertical representa os valores alcançados, de 0 a 14, nos conteúdos de Ciências Humanas e Linguagens. Os cotistas possuem médias iniciais de desempenho inferiores a $50 \%$ (14,5 em 30 pontos), o que se representa com a concentração de pontos na região inferior-esquerda do gráfico. De maneira inversa, os ingressos por ampla concorrência possuem médias iniciais acima dos 50\% (17,5 em 30 pontos), distribuídos, de maneira geral, na área superior-direita do gráfico.

Gráfico 1 - Distribuição de notas do processo seletivo para ingresso no IFNMG.

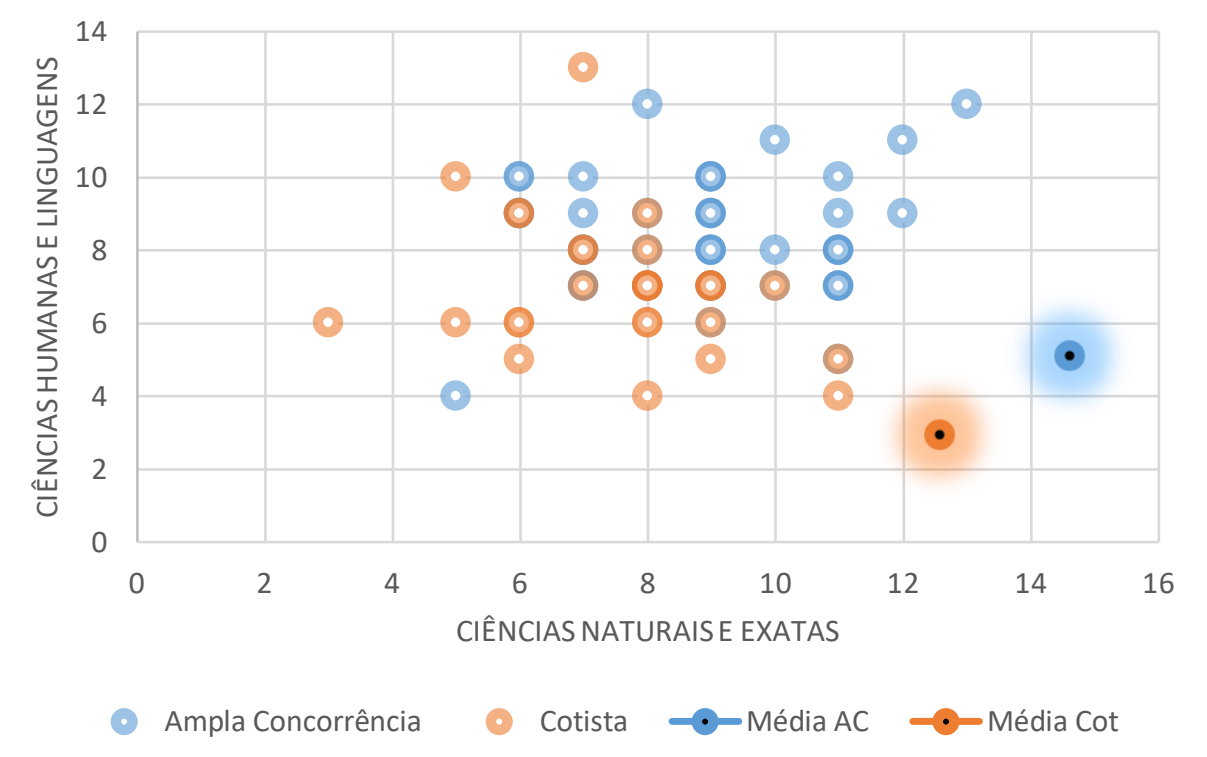

Fonte: Elaborado pelo autor (2019). 
A diferença média do desempenho de cotistas e não cotistas, aferidas pela avaliação de ingresso na instituição, pode ser medida percentualmente em 16,2 pontos favoravelmente aos não cotistas. Essa distância achata-se progressivamente ao longo dos cursos, aproximando a diferença de rendimento acadêmico entre os dois grupos, por exemplo, entre diferenças médias acumuladas de apenas 3,3\% (Tab. 3).

Tabela 3 - CRA acumulado por curso e quota amostral.

Média de CRA acumulado

\begin{tabular}{lrrrrrr} 
& Não Cotistas & \multicolumn{1}{c}{ Cotistas } & \multicolumn{2}{c}{ VRRI } & \multicolumn{2}{c}{ VRRS } \\
& & & & \multicolumn{2}{c}{ PPI } & \multicolumn{1}{c}{ PPI } \\
AGROPECUÁRIA & 76,0 & 72,4 & 74,26 & 72,6 & 71,5 & 69,4 \\
INFORMÁTICA & 77,4 & 75,7 & 74,3 & 78,0 & 76,8 & 72,0 \\
ZOOTECNIA & 73,8 & 71,7 & 71,4 & 72,2 & 72,2 & 69,8 \\
\hline
\end{tabular}

Fonte: Elaborado pelo autor (2019). Destaque em verde para as maiores médias de cada curso.

Esse resultado é expressivo se considerarmos que a cidade de Almenara possui baixo Índice de Desenvolvimento da Educação Básica (IDEB) para os anos finais do Ensino Fundamental, ocupando a posição nacional no terceiro quartel da lista (MEC; INEP, 2016). Apesar do índice de desigualdade inicial, potencializado por baixas condições educacionais durante o ensino fundamental, o desempenho médio de saída das turmas formadas em 2017, 2018 e 2019, considerando os microdados do Exame Nacional do Ensino Médio (ENEM), é superior à média das notas de estudantes de outras escolas da região (INEP, 2020). Miranda (2017) realiza uma análise semelhante com estudantes do Instituto Federal do Sudeste de Minas Gerais. Os resultados indicam que, ao fim dos três anos do ensino médio, os estudantes cotistas apresentam CRA superior aos não cotistas. A divergência com os nossos resultados pode ser explicada, em parte, pelo contexto social daquela instituição, cujos campus localizam-se em cidades com IDEB e IDH, por exemplo, mais elevados.

Do ponto de vista nacional, Sousa et al. (2019) mostra que a rede federal de educação profissional e tecnológica possui melhor desempenho nas quatro áreas do conhecimento (Linguagens e Códigos, Ciências da Natureza, Ciências Humanas e Matemática) do ENEM em comparação com escolas estaduais, municipais e privadas. 
Além disso, o desempenho dos estudantes da rede federal equipara-se, em matemática, leitura e ciências naturais, ao desempenho médio de estudantes de países considerados modelos educacionais, como Alemanha, Coreia do Sul e Estados Unidos (SOUSA, 2019, p. 134).

De maneira geral, as médias de CRA acumuladas por trimestre variaram pouco: entre 71,7 e 77,5 (Tab. 3). Quando as médias amostrais são aproximadamente iguais, recomenda-se comparar os desvios-padrão das amostras (TRIOLA, 2015, p. 85). Além disso, observa-se a linha de medida vertical do desvio-padrão entre os valores de dados (Gráf. 2). O desvio-padrão do CRA da turma de Agropecuária diminui ao longo do ano, partindo de 7,43 no $1^{\circ}$ ano para 4,45 no último ano. A mesma tendência é observada nas séries históricas de Informática (de 5,64 para 5,14) e de Zootecnia (de 4,42 para 4,06). O Gráfico 2 oferece uma visão comparativa das médias de notas nos três cursos durante os três anos. O Gráfico 3 compara essas médias entre cotistas e não-cotistas, desde as notas utilizadas para ingresso na instituição.

Gráfico 2 - Desvios-padrão distribuídos em frequência por curso.

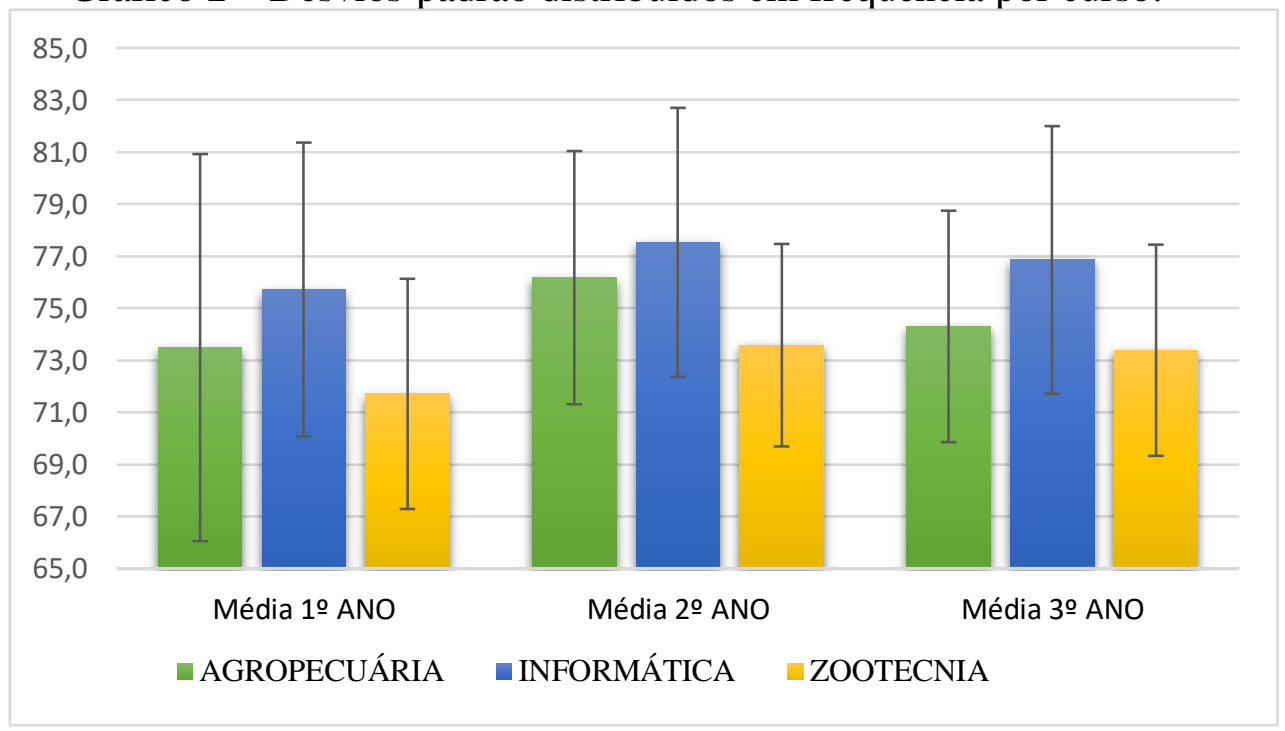

Fonte: Elaborado pelo autor (2019). As linhas verticais representam o desvio-padrão. 
Gráfico 3 - Comparação entre as médias de CRA.

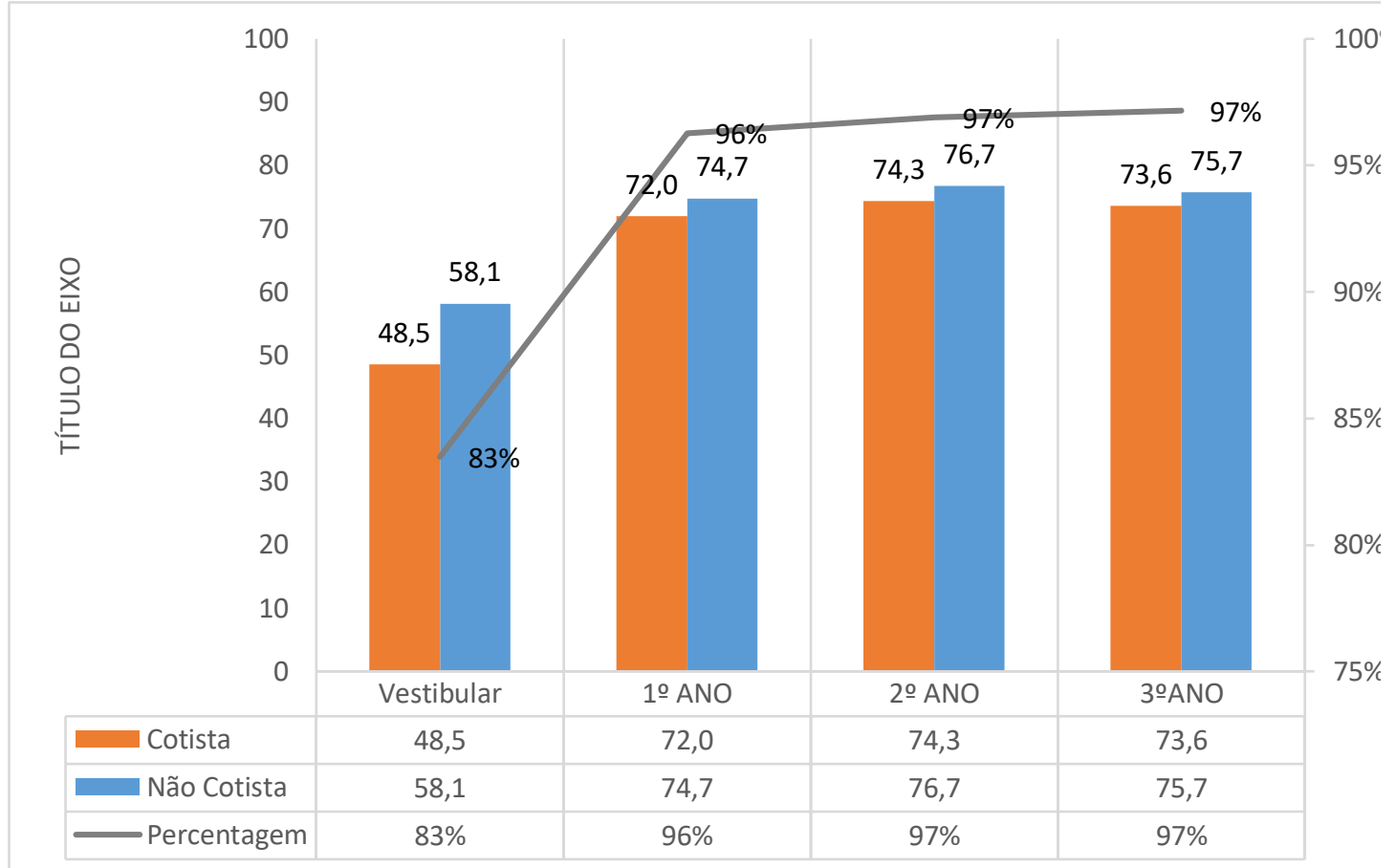

Fonte: Elaborado pelo autor (2019). A linha de porcentagem mostra a diferença entre o CRA de não cotistas e cotistas.

Em conjunto, esses resultados sugerem o processo de homogeneização das notas em uma turma de alunos no decorrer da vida acadêmica, diminuindo a amplitude de variação individual, seja entre cotistas e não cotistas ou entre membros de um mesmo subgrupo de cotistas. Após exame adicional do desvio-padrão dentro das amostras (Tab. 4), percebeu-se menor variação de amplitude entre os cotistas, em média uma diferença de $35 \%$, sugerindo que o processo de homogeneização ocorre de maneira mais aguda entre os não-cotistas. É preciso dizer que a metodologia adotada exclui das médias os alunos evadidos e retidos de ambas as amostras. A retenção e a evasão ocorreram em ambos os grupos, dirimindo a possibilidade de viés dos dados da pesquisa. Ademais, pesquisas recentes mostram que a evasão possui causas multifatoriais que tomam o desempenho acadêmico como um índice entre outros (RAMOS NETO, 2019; ALVARES; MATOS, 2020). 
Tabela 4 - Análise de variância por curso.

\begin{tabular}{llrrrrr}
\hline \multirow{2}{*}{ Curso } & \multicolumn{1}{c}{ Tratamento } & Média & Alunos & $\begin{array}{c}\text { desvio- } \\
\text { padrão }\end{array}$ & F & $\begin{array}{c}\boldsymbol{\alpha}= \\
\text { p-valor }\end{array}$ \\
\hline \multirow{2}{*}{ AGROPECUÁRIA } & Não-Cotista & 76,0 & 15 & 5,7 & \\
& Cotista & 72,4 & 9 & 4,0 & 2,70 & 0,114 \\
\cline { 2 - 6 } INFORMÁTICA & Total & 74,7 & 24 & 5,3 & & \\
\hline \multirow{2}{*}{ Não-Cotista } & 77,4 & 15 & 5,9 & & \\
& Cotista & 75,7 & 10 & 3,3 & 0,64 & 0,431 \\
& Total & 76,7 & 25 & 5,0 & & \\
\hline \multirow{2}{*}{ ZOOTECNIA } & Não-Cotista & 73,8 & 13 & 4,4 & & \\
& Cotista & 71,7 & 10 & 2,9 & 1,70 & 0,206 \\
\cline { 2 - 6 } & Total & 72,9 & 23 & 3,9 & & \\
\hline
\end{tabular}

Fonte: Elaborado pelo autor (2019).

A análise de variância das médias de CRA permitiu observar os índices de alunos cotistas e não-cotistas, de modo a estabelecer um critério de significância estatística para a comparação dos dados amostrais. Estabeleceu-se como nível de significância $\alpha=0,05$, sendo que a hipótese nula seria rejeitada caso o valor $p$ (de probabilidade) fosse menor do que $0,5(H: \mathrm{p}>0,5)$. Nos três cursos, o p-valor esteve acima do valor de teste, de modo a concluir-se que não é possível rejeitar a hipótese de que não exista significância estatística entre alunos que ingressaram pelo sistema de cotas e os demais. Além disso, é preciso salientar que os baixos valores de F (Tab. 4) sugerem pouca significância da diferença entre médias amostrais, uma vez que se avalia a dispersão de pontos em relação à média. No curso de Agropecuária, a variabilidade das médias entre os grupos cotistas e não-cotistas é grande em relação à variação de coeficientes dentro de cada grupo. Chaves et al. (2020, p. 690) apresentam resultados semelhantes em relação ao menor desempenho dos cotistas durante o curso. Araújo (2019) apresenta resultados que indicam que estudantes da ampla concorrência tendem a ter rendimento homogêneo, independente da disciplina, ao passo que o mesmo não se observa entre cotistas. Nesse sentido, recomenda-se ações reparativas em relação ao déficit de aprendizagem dos cotistas.

Os não-cotistas possuem as médias de nota mais altas nos cursos Agropecuária e Zootecnia, ao passo que as piores médias são dos que ingressaram por meio de vagas reservadas para estudante com renda familiar bruta superior a 1,5 salário-mínimo per capita e que se autodeclararam pretos, pardos ou indígenas (Tab. 3). A partir dos dados aferidos, três razões podem explicá-lo. Em primeiro lugar, o número de alunos nessa 
classe de reserva de vagas (apenas 5) é baixo a ponto de não podermos mensurar a margem de erro. Em segundo lugar, seria necessário realizar uma pesquisa qualitativa, em complemento a esta, que averiguasse, por exemplo, as condições sociais e escolares prévias, para se deduzir a razão da diferença estatística. Em terceiro lugar, pode-se levantar a hipótese de que os alunos que entram por reserva de vagas no IF, isto é, aqueles que estão classificados nas últimas posições, tem mais propensão à retenção do que os demais.

\section{CONSIDERAÇÕES FINAIS}

O último artigo da Lei 12.711/2012 estabelece o prazo de 10 anos para a revisão da política pública de cotas para ingresso em cursos da rede federal de ensino. Na eminência desta revisão, o presente estudo indicou o sucesso das ações afirmativas em relação ao desempenho acadêmico e ao combate à desigualdade educacional. O objetivo da pesquisa foi comparar o rendimento acadêmico de cotistas e não-cotistas dos cursos técnicos integrados, de modo a subsidiar quantitativamente as ações dos programas de assistência aos alunos em situação de vulnerabilidade social. Os dados amostrais apoiam a afirmativa de que o rendimento acadêmico de alunos cotistas e não cotistas tendem a se tornar homogêneos. Embora o principal indicador de desempenho acadêmico (notas em avaliações formais) tenha limitações, pode-se reuni-lo a outros indicadores para compreender a questão, pelo menos, no âmbito regional. O fenômeno da evasão escolar é multifatorial. Por isso, para gerar efeitos concretos sobre as políticas públicas locais, a pesquisa deverá avançar sobre dados relacionados à evasão, com diagnósticos sobre a comparação entre grupos de cotistas, à retenção escolar, com avaliação das médias de rendimento acadêmico de disciplinas e áreas do conhecimento.

As pesquisas sobre desempenho acadêmico de cotistas estão, em sua maioria, direcionadas para os cursos superiores das Universidades Públicas, cujo sistema de ingresso por cotas acontece por meio do Sistema de Seleção Unificada (SISU). Embora o sistema se justifique pela potencial democratização do acesso ao ensino superior, ele pode ser aperfeiçoado, já que não inclui nos “cursos de elite" número expressivo de estudantes cotistas, especialmente aqueles de renda baixa (GUERRINI et al., 2018, p. 20). Esse sistema tende a concentrar os beneficiários nos cursos de menor concorrência e 
prestígio social. Pode-se verificar, em alguns destes cursos, diferença significativa entre os cotistas e os não-cotistas (PINHEIRO, 2014; GUERRINI et al., 2018, p. 29-30).

Os dados apresentados sustentam a hipótese de que não é trivial a relação entre raça/cor e desempenho acadêmico desde a educação básica, mesmo no coorte das escolas públicas. Para o NAPNE, o NAE e a Assistência Estudantil, essa base de dados pode servir de apoio aos alunos com propensão à retenção e à evasão, quais sejam, aqueles que têm as menores notas no processo seletivo, estudantes com renda familiar bruta superior a 1,5 salário-mínimo per capita e se autodeclararam pretos, pardos ou indígenas. Nestes casos, deve-se dar maior atenção aos estudantes do grupo VRRI-PPI que ingressaram com as notas mais baixas, pois, como sugerem Figueiredo e Salles (2017), pode haver correlação entre retenção e evasão escolar na educação profissional.

Estudos complementares sobre o sistema de reserva de vagas no Ensino Médio podem dirimir essas dificuldades, determinando outras variáveis, por exemplo, o gênero, a idade e dados relativos à evasão escolar. Além disso, este tipo de pesquisa quantitativa pode avaliar os níveis de eficácia escolar. São necessárias, ainda, pesquisas de desempenho acadêmico do mesmo curso, em campus e instituições diferentes. Resta, ainda, reconsiderar as políticas de acesso dos cotistas, incluindo-as nos planos de permanência e êxito (PINHEIRO, 2020) e adequando-as ao perfil do profissional dos cursos e ao contexto social das unidades de ensino. Em 2019, por exemplo, a maioria das unidades da Rede EPT adotou como processo seletivo o exame vestibular com questões de múltipla escolha (BRASIL [PNP], 2019), método incapaz de avaliar elementos centrais do perfil do candidato, tais como o cognitivo, o afetivo, o estético e, sobretudo, o profissional.

Considerando a política global de acesso aos cursos de nível médio do IFNMG, distribuídos em seus 11 campi, é possível, ainda, ampliar o tamanho da população em exame, o que pode interferir positivamente na relevância estatística da pesquisa. Pode-se, por fim, estabelecer outros parâmetros de pesquisa, tais como a média por disciplina, isto é, a média aritmética da pontuação obtida em cada disciplina, por ano cursado, e a média por área temática, isto é, a média ponderada obtida dentro de uma das grandes áreas do conhecimento, conforme divisão do Ministério da Educação para a aplicação do ENEM. 


\section{REFERÊNCIAS BIBLIOGRÁFICAS}

ADAMS, Elias. A política de cotas e de permanência: uma análise do triênio 2015-2017 do IFFar Campus Santo Ângelo. Revista de Ciência e Inovação, v. 4, n. 1, p. 8-21, jul. 2019. Disponível em https://doi.org/10.26669/2448-4091207.

ALVAREZ, Karine Rodrigues; MATOS, Roberta Pereira. PERMANÊNCIA E ÊXITO ESCOLAR NOS INSTITUTOS FEDERAIS. Ensino em Foco, v. 3, n. 6, p. 106-115, set. 2020. Disponível em:

https://publicacoes.ifba.edu.br/index.php/ensinoemfoco/article/view/681. Acesso em 21 abr. 2021.

ALVES, Lindgren. A Conferência de Durban contra o Racismo e a responsabilidade de todos. Revista Brasileira de Política Internacional, v.45, n. 2, Brasília, jul.-dez. 2002.

ARAÚJO, Adélia Victórya Bezerra de. Reserva de vagas e desempenho acadêmico no IFRN: um estudo a partir dos coeficientes de rendimento. 2019. 47 f. TCC (Graduação) - Curso de Licenciatura em Matemática, Instituto Federal de Educação, Ciência e Tecnologia do Rio Grande do Norte, Natal, 2019. Disponível em: https://memoria.ifrn.edu.br/handle/1044/1656. Acesso em 19 abr. 2021.

BARROSO, Roberto. 2012. Inteiro Teor do Acórdão da Ação Declaratória de Constitucionalidade 41. Brasília: Supremo Tribunal Federal. Disponível em: http://redir.stf.jus.br/paginadorpub/paginador.jsp?docTP=TP\&docID=13375729. Acesso em 4 jun. 2020.

BIROCHI, Renê. Metodologia de estudo e de pesquisa em administração. Florianópolis: Departamento de Ciências da Administração / UFSC; Brasília: CAPES: $\mathrm{UAB}, 2015$.

BRASIL. Lei n ${ }^{\circ} 12.711$, de 29 de agosto de 2012. Dispõe sobre o ingresso nas universidades federais e nas instituições federais de ensino técnico de nível médio e dá outras providências. Diário Oficial [da] República Federativa do Brasil. Poder Executivo, Brasília, DF, 30 ago. 2012, Seção 1, p. 1.

BRASIL. PLATAFORMA NILO PEÇANHA [PNP]. (Comp.). Rede Federal de Educação Profissional, Científica e Tecnológica. SETEC/MEC: PNP 2019. 2019. Disponível em: http://plataformanilopecanha.mec.gov.br/2019.html. Acesso em: 21 out. 2020.

CAMPOS, Luis Augusto. Enquadrando a esfera pública: a controvérsia das cotas raciais na imprensa. Tese (Doutorado em Sociologia). 2013. 276 f. Universidade do Estado do Rio de Janeiro, Rio de Janeiro, 2013. 
CASTRO, Sabrina Olimpio et al. A política de cotas sociais para o acesso ao ensino superior: o caso das universidades federais mineiras. Revista Gestão Universitária na América Latina - GUAL, Florianópolis, p. 256-279, fev. 2017.

CHAVES, Kelson Gérison Oliveira; ASSIS, Sandra Maria de; ARAÚJO, Heloísa Medeiros de; SOUZA, Deickson Lennon Galvao de; CAMPOS, Camila Goulart de. Permanência e Êxito Escolar: análise do desempenho acadêmico de estudantes ingressantes no ensino médio integrado do IFRN/Caicó através das cotas étnico-raciais no ano de 2014. Revista Educação e Políticas em Debate, v. 9, n. 3, p. 672-691, 24 out. 2020 .

DOMINGUES, Petrônio. Movimento Negro Brasileiro: alguns apontamentos históricos. Tempo [online]. vol.12, n.23, p.100-122, 2007.

FAVERI, Dinorá Baldo de; PETTERINI, Francis Carlo; BARBOSA, Marcelo Ponte. Uma avaliação dos impactos de expansão dos Institutos Federais nas economias dos municípios brasileiros. Planejamento e Políticas Públicas. n. 50. vol. 1. jan.-jun. 2018, p. 125-147.

FERES JUNIOR, João. Comparando justificações das políticas de ação afirmativa: EUA e Brasil. Achegas.net - Revista de Ciência Política. n. 30, jul.-ago. 2006.

FIGUEIREDO, Natália Gomes da Silva; SALLES, Denise Medeiros Ribeiro. Educação Profissional e evasão escolar em contexto: motivos e reflexões. Ensaio: aval. pol. públ. Educ., Rio de Janeiro, v. 25, n. 95, p. 356-392, abr. 2017. Disponível em http://www.scielo.br/scielo.php?script=sci_arttext\&pid=S0104$40362017000200356 \& \operatorname{lng}=$ en\&nrm=iso. Acesso em 20 abr. 2021.

GUERRINI, Daniel et al. Acesso e democratização do ensino superior com a Lei $\mathrm{n}^{\circ}$ 12.711/2012: o câmpus de Londrina da Universidade Tecnológica Federal do Paraná (UTFPR). Revista Brasileira de Estudos Pedagógicos, Brasília, v. 99, n. 251, p. 1736, jan. 2018.

GUIMARÃES, Nadya Araujo; ANDRADA, Ana Carolina; PICANÇO, Monise Fernandes. Transitando entre universidade e trabalho: trajetórias desiguais e políticas afirmativas. Cadernos de Pesquisa, São Paulo, v. 49 n. 172, p.284-310 abr./jun. 2019

INSTITUTO BRASILEIRO DE GEOGRAFIA E ESTATÍSTICA [IBGE]. Desigualdades Sociais por Cor ou Raça no Brasil. Estudos e Pesquisas - Informação Demográfica e Socioeconômica, n. 41, 2019. Disponível em https://biblioteca.ibge.gov.br/visualizacao/livros/liv101681 informativo.pdf. Acesso em 7 jun. 2020.

INSTITUTO DE PESQUISA ECONÔMICA APLICADA [IPEA]. Igualdade Racial. Relatório elaborado por Luciana Jaccoud, Adailton Silva, Waldemir Rosa e Cristiana Luiz. Políticas Sociais: acompanhamento e análise. $n^{\circ}$ 17, 2009. p. 313-367. 
INSTITUTO NACIONAL DE ESTUDOS E PESQUISAS EDUCACIONAIS ANÍSIO TEIXEIRA [INEP]. Microdados [plataforma virtual]. Brasília, atualizado em 23 mar. 2020. Disponível em http://inep.gov.br/microdados. Acesso em 8 jun. 2020.

KARRUZ, Ana. Oferta, Demanda e Nota de Corte: Experimento Natural sobre Efeitos da Lei das Cotas no Acesso à Universidade Federal de Minas Gerais. DADOS Revista de Ciências Sociais, Rio de Janeiro, v. 61, n. 2, p. 405-462, 2018.

LEWANDOWSKI, Ricardo. 2012. Íntegra do Voto do Relator da Arguição de Descumprimento de Preceito Fundamental 186. Brasília: Supremo Tribunal Federal. Disponível em:

http://www.stf.jus.br/PORTAL/cms/verNoticiaDetalhe.asp?idConteudo=205890. Acesso em 11 fev. 2018.

MÉSZÁROS, István. Reflexões sobre a nova internacional. Margem Esquerda: ensaios marxistas. São Paulo, n. 22, p. 67-90, abr. 2014.

MINISTÉRIO DA EDUCAÇÃO [MEC]. Portaria Normativa nº 18. Publicada no DOU de 17/10/2012 (n. 201, Seção 1, p. 104). Disponível em: http://portal.mec.gov.br/cotas/docs/portaria_18.pdf Acesso em 10 fev. 2018.

MINISTÉRIO DA EDUCAÇÃO [MEC]; INSTITUTO NACIONAL DE ESTUDOS E PESQUISAS EDUCACIONAIS ANÍSIO TEIXEIRA [INEP]. IDEB - Anos finais do ensino fundamental: MEC/INEP - Censo Escolar, 2016.

MINISTÉRIO DA EDUCAÇÃO [MEC]. Portaria Normativa n 13. Publicada no DOU de 12/05/2016 (n. 90, Seção 1, p. 47). Disponível em:

http://pesquisa.in.gov.br/imprensa/jsp/visualiza/index.jsp?jornal $=1 \&$ data $=12 / 05 / 2016 \&$ pagina $=47$. Acesso em 4 jun. 2020.

MIRANDA, Emmanuella Aparecida. A política de cotas no Instituto Federal de Educação, Ciência e Tecnologia do Sudeste de Minas Gerais: análise do acesso e da permanência. 2017. 224f. Dissertação (Mestrado) - Programa de Pós-Graduação em Educação, Universidade Federal de Viçosa. Viçosa, 2017. Disponível em https://locus.ufv.br//handle/123456789/24337. Acesso em 20 abr. 2021.

MONSTELLER, Frederick; MOYNIHAN, Daniel P. Um relatório inovador. In: Nigel Brooke, José Francisco Soares (Org.). Pesquisa em eficácia escolar: origens e trajetórias. Belo Horizonte: Editora UFMG, 2008, p. 33-49.

PINHEIRO, Juliene. Desempenho acadêmico e sistema de cotas. Dissertação (Mestrado). Programa de Pós-Graduação em Gestão Pública. 2014. 101 f. Universidade Federal do Espírito Santo, Vitória, 2014.

PINHEIRO, Carina Lilian Fernandes. Serviço social e cotas: desafios para a permanência dos estudantes no Instituto Federal do Rio Grande do Norte. Dissertação (Mestrado). Programa de Pós-Graduação em Serviço Social. 2020. 177f. Universidade Federal da Paraíba, João Pessoa, 2020. 
PIOVESAN, Flavia. Ações afirmativas da perspectiva dos direitos humanos. Cad. Pesqui. [online], v. 35, n. 124, 2005, p.43-55.

QUEIROZ, Delcele Mascarenhas; SANTOS, Jocélio Teles dos. Sistema de cotas: um debate: dos dados à manutenção de privilégios e de poder. Educação e Sociedade. $\mathrm{n}$. 27, vol. 96 - Especial, 2006, p. 717-737.

RAMOS NETO, João Oliveira. A evasão escolar nos Institutos Federais de Educação, Ciência e Tecnologia: uma análise dos planos estratégicos de permanência e êxito.

Educação em Revista, v. 20, n. 2, p. 7-25, jul.-dez., 2019. Disponível em: https://doi.org/10.36311/2236-5192.2019.v20n2.02.p7.

RAWLS, John. Justiça como Equidade: Uma Reformulação. Trad. de Cláudia Berliner. São Paulo: Martins Fontes, 2003.

RUA, Maria das Graças. Políticas públicas. 3. ed. Florianópolis: Departamento de Ciências da Administração / UFSC; [Brasília]: CAPES/UAB, 2014.

SOUSA, L. A., SANTOS, M. I. A., LOPES, J. M. R., ALMEIDA, G. S., \& PONTES JUNIOR, J. A. F. Desempenho das Instituições Federais de Educação Profissional, Científica e Tecnológica Brasileiras no ENEM. Tendências Pedagógicas, n. 34, p. 128$138,2019$.

\section{SUPREMO TRIBUNAL FEDERAL [STF]. Medida Cautelar em arguição de} Descumprimento de Preceito Fundamental 186-2. Distrito Federal, 31 de julho de 2009. Disponível em: http://www.stf.jus.br/arquivo/cms/noticiaNoticiaStfArquivo/anexo/ADPF186.pdf. Acesso em 10 fev. 2018.

TRIOLA, Mário F. Introdução à estatística: atualização da tecnologia. Tradução de Ana Maria Lima de Farias, Vera Regina L. Flores. Rio de Janeiro: LTC, 2015.

VELLOSO, Jacques. Cotistas e não cotistas: rendimento de alunos da Universidade de Brasília. Cadernos de Pesquisa. n. 39 (137), p. 621-644, 2009.

WEISSKOPF, Thomas. A experiência da Índia com ação afirmativa na seleção para o Ensino Superior. In: Jonas Zonisein; João Feres Júnior. Ação afirmativa no Ensino Superior. Belo Horizonte: Editora UFMG; Rio de Janeiro: IUPERJ, 2008, p. 35-60. 